\title{
White coat syndrome and its variations: differences and clinical impact
}

This article was published in the following Dove Press journal: Integrated Blood Pressure Control

\author{
Mariana R Pioli' \\ Alessandra MV Ritter' \\ Ana Paula de Faria' \\ Rodrigo Modolo ${ }^{1,2}$ \\ 'Department of Pharmacology, \\ School of Medical Sciences, \\ University of Campinas \\ (UNICAMP), Campinas, Sao Paulo, \\ Brazil; '2Laboratory of Cardiac \\ Catheterization, Department of \\ Internal Medicine, Cardiology \\ Division, School of Medical Sciences, \\ University of Campinas (UNICAMP), \\ Campinas, Sao Paulo, Brazil
}

\begin{abstract}
Hypertension is closely linked to increased cardiovascular risk and development of target organ damage (TOD). Therefore, proper clinical follow-up and treatment of hypertensive subjects are mandatory. A great number of individuals present a variation on blood pressure (BP) levels when they are assessed either in the office or in the out-of-office settings. This phenomenon is defined as white coat syndrome - a change in BP levels due to the presence of a physician or other health professional. In this context, the term "white coat syndrome" may refer to three important and different clinical conditions: 1) white coat hypertension, 2) white coat effect, and 3) masked hypertension. The development of TOD and the increased cardiovascular risk play different roles in these specific subgroups of white coat syndrome. Correct diagnose and clinical guidance are essential to improve the prognosis of these patients. The aim of this review was to elucidate contemporary aspects of these types of white coat syndrome on general and hypertensive population.
\end{abstract}

Keywords: hypertension, white coat effect, white coat hypertension, masked hypertension, cardiovascular risk

\section{Introduction}

Hypertension is an increasingly important medical and public health problem. ${ }^{1,2} \mathrm{Blood}$ pressure (BP) levels are related to the risk of cardiovascular disease (CVD) - the higher the BP levels, the greater the CVD risk. Studies have shown that for each increase of $20 \mathrm{mmHg}$ in systolic blood pressure (SBP) or $10 \mathrm{mmHg}$ in diastolic blood pressure (DBP) levels, a doubling of death or CVD risk was found. ${ }^{3}$ Therefore, the accurate diagnose of hypertension and measurement of BP levels are mandatory for a successful management of hypertensive patient. ${ }^{4}$

Variation on BP levels throughout the day is very common, but it has been observed that a portion of population has higher BP levels when obtained by medical personnel compared to the levels obtained by themselves. ${ }^{5}$ When this difference is relevant and confirmed by 24-hour ambulatory blood pressure monitoring (ABPM), it reveals the clinical conditions defined as "white coat syndrome," which comprises: 1) white coat effect (WCE), 2) white coat hypertension (WCH), and 3) white coat normotension or masked hypertension (MH).

White coat syndrome is a common phenomenon noted in both hypertensive and normotensive subjects. ${ }^{6}$ Some authors attribute this BP elevation effect to a neuro-endocrine reflex mediated by sympathetic nervous system ${ }^{7}$ conditioned by the
Correspondence: Rodrigo Modolo Laboratory of Cardiac Catheterization, Department of Internal Medicine, Cardiology Division. School of Medical Science, University of Campinas (UNICAMP), Vital Brasil, 25I University City "Zeferino Vaz", ZIP Code |3084-97|, Campinas, Sao Paulo, Brazil Tel +55 1935218788

Email rodrigo_modolo@yahoo.com.br 
anticipated concerning of having a further illness during the BP measurement. ${ }^{5}$ Although it is known that anxiety elevates $\mathrm{BP}$ and heart rate levels, it does not seem to be the trigger for the white coat episodes in the population. ${ }^{8}$

If WCE and WCH are not correctly identified, both the conditions may contribute to unnecessary initiation (WCH) or intensification (WCE) of antihypertensive treatment. In addition, WCE has been wrongly implicated in pseudoresistance to antihypertensive treatment and/or uncontrolled hypertension diagnoses which may result in an underestimation of the office BP control rates. ${ }^{9}$ Although the high cardiovascular $(\mathrm{CV})$ risk in uncontrolled hypertensive patients is well established, the $\mathrm{CV}$ risk on $\mathrm{WCE}$ and $\mathrm{WCH}$ remains not completely elucidated. ${ }^{10}$

$\mathrm{MH}$ also deserves clinical attention considering its association with the development of target organ damage (TOD), ${ }^{11}$ increased CV risk, and all-cause mortality compared to normotensive and $\mathrm{WCH}$ subjects. ${ }^{12}$

In this concern, understanding the predictors and mechanisms underlying the conditions grouped as "white coat syndrome" is important to correctly classify and define their management. The aim of this review was to gather information on the current knowledge on these subgroups that compose the so-called white coat syndrome in the general and hypertensive population to better understand and manage these conditions.

\section{Hypertension and white coat syndrome}

A new definition was proposed by the American College of Cardiology and American Heart Association classifying hypertension for values of SBP $\geq 130 \mathrm{mmHg}$ or DBP $\geq 80$ $\mathrm{mmHg}$. This modification relies on the fact that achieving these values is thought to prevent even more CVD. ${ }^{10} \mathrm{Nev}-$ ertheless, the 2018 Guidelines of the European Society of Hypertension (ESH) and European Society of Cardiology (ESC) maintained the same definition of arterial hypertension as in the previous guideline $(2013)^{13}$ - office values of SBP $\geq 140 \mathrm{mmHg}$ and/or DBP $\geq 90 \mathrm{mmHg}$, arguing that the clinical studies analyzed provide data for the classification of $\mathrm{BP}$ and the definition of hypertension to remain unchanged in relation to previous ESH/ESC guidelines. ${ }^{14}$

A much-discussed study in these guidelines is the Systolic Blood Pressure Intervention Trial (SPRINT). It comprises important information on the most appropriate treatment for SBP. The authors have shown a $25 \%$ reduction in CV morbidity and mortality with SBP $<120 \mathrm{mmHg}$ (intensive treatment) when compared to the reduction to $<140 \mathrm{mmHg}$ (standard treatment) in hypertensive individuals with high $\mathrm{CV}$ risk and non-diabetics. ${ }^{15}$ However, its reproducibility was questioned due to the way the measurement of BP was obtained. The method used (automatic BP measurement without the presence of an observer) is not in accordance with clinical practice nor with other randomized controlled trials. In practice, such method results in lower BP values when compared to the conventional office BP, in addition to the non-detection of phenomena related to white coat syndrome, such as WCH and WCE. ${ }^{10,14}$ Although this work has highlighted important data on the management of treatment in hypertensive patients, it is suggested that its applicability does not extend to the treatment of patients with white coat syndrome.

One of the new recommendations in 2018 Guidelines for ESC/ESH was the wider use of outpatient BP measurements by ABPM and home blood pressure monitoring (HBPM) in order to diagnose phenomena related to "white coat syndrome," which includes WCE, WCH, and MH. ${ }^{14}$ The steps for diagnosing each condition mentioned above are summarized in the flowchart of Figure 1.

\section{White coat effect}

Treated hypertensives may have elevated office BP levels, induced by the presence of the physician or health care professional, which is called WCE. ${ }^{16}$ The diagnosis is confirmed when the office BP presents a clinically significant elevation (>20 mmHg for SBP and >10 mmHg for DBP) when compared to out-of-office measurements of ABPM or HBPM. ${ }^{10}$ This condition should be well evaluated as it may give the false impression of uncontrolled hypertension and the necessity of adequacy of individual's drug therapy. ${ }^{17}$

This phenomenon was associated with higher heart rate levels and non-dipping of nocturnal BP - fail in decrease of $10 \%$ of BP on nocturnal levels. ${ }^{18}$ These outcomes reinforce the hypothesis that WCE is mediated by the overactivity of the sympathetic nervous system; and the subjects may evolve toward a worse prognosis, since the association of non-dipping with TOD and CVD risk is well known. ${ }^{19}$ The WCE presents a high prevalence in patients with resistant hypertension (individuals with BP above the recommended level, despite the concomitant use of three antihypertensive agents, being one diuretic and prescribed in ideal doses) ${ }^{9}$ and is also closely related to ischemia silent myocardium in this group. ${ }^{20}$

Some studies have found a correlation between WCE and arterial stiffness. ${ }^{21,22}$ Despite one study did not use the pulse wave velocity, the gold standard method, they believe that the 


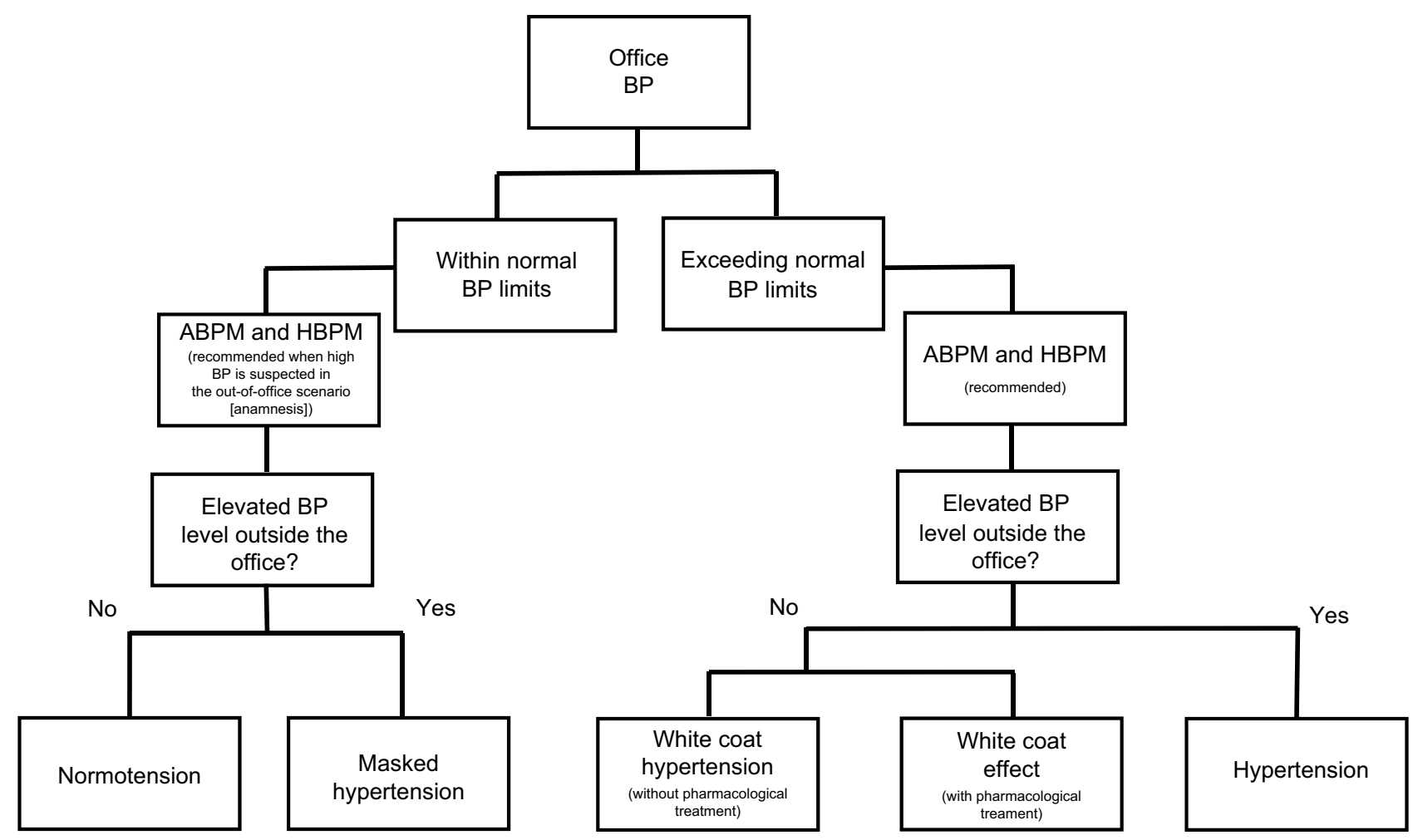

Figure I Flowchart of the pathway to diagnosis/classify the white coat syndrome according to the BP levels. Note: Steps for diagnosis of normotension, hypertension, and phenomena related to white coat syndrome. Abbreviations: ABPM, ambulatory BP monitoring; BP, blood pressure; HBPM, home BP monitoring.

WCE may be the clinical manifestation of impaired arterial compliance and might therefore be a sign of severity in the context of stable arterial hypertension. ${ }^{21}$ Additionally, they reported that WCE may be caused by the arterial aging since they found a correlation between WCE and the amplitude of the backward pressure wave, which suggest increased arterial stiffness. ${ }^{22}$

WCE appears to be a less damaging phenomenon inside the group of white coat syndrome. All studies have shown a weak or low relationship between WCE and TOD development in patients with mild-to-moderate hypertension ${ }^{23}$ and also in resistant hypertensives. ${ }^{24}$

\section{White coat hypertension}

It is worth noting that WCE and $\mathrm{WCH}$ are often wrongly used as the same term, so one must be careful not to misinterpret these phenomena.

$\mathrm{WCH}$ is characterized when the individual without antihypertensive treatment presents high BP levels (above the reference to be characterized as hypertensive) in the office, but with normal readings when measured by ABPM or HBPM. ${ }^{10,17}$ Thus, if we only the office reading was observed, the patients would falsely be characterized as hypertensive; therefore, the correct nomenclature is $\mathrm{WCH}$. This condition is nevertheless a subgroup of the WCE. It is diagnosed after at least three occasions when office BP is $\geq 140 / 90 \mathrm{mmHg}$ when the mean 24-hour ABPM is <135/85 mmHg. ${ }^{14}$

This phenomenon accounts for up to $25 \%-30 \%$ of subjects attending outpatient hypertension centers. The prevalence is higher in female sex, obese, and it seems to increase according to the age. ${ }^{25}$ Some authors believe that $\mathrm{WCH}$ is an intermediate stage between normotensive and hypertensive conditions. ${ }^{26}$ A study demonstrated that patients with $\mathrm{WCH}$ condition had 2.5-fold higher chances to develop a sustained hypertension compared to normotensive subjects. ${ }^{26}$ Hence, it should no longer be considered a harmless clinical state since there is a correlation between sustained high BP levels with the development of TOD and consequent increase in $\mathrm{CV}$ risk.

WCH was independently associated with arterial stiffness in treated hypertensive individuals. ${ }^{27}$ Also, a study has shown that subjects with WCH had a worse vascular function and a greater CV mortality compared to pre-hypertensives. ${ }^{28}$ Andrikou et $\mathrm{al}^{29}$ observed that $\mathrm{MH}$ and $\mathrm{WCH}$ presented lower pulse wave velocity when compared with individuals with sustained arterial hypertension, and these two phenomena 
were associated with a higher inflammatory grade and arterial stiffening when compared with normotensive subjects. In addition, some $\mathrm{WCH}$ and normotensive studies have found a slight worsening in the elastic properties of the aorta in individuals with $\mathrm{WCH}$, but when this group is compared to individuals with sustained hypertension, the results are controversial. ${ }^{30,31}$ These findings may reinforce the hypothesis that subjects with WCH develop more CVD than normotensive individuals. ${ }^{31}$

Recently, Androulakis et $\mathrm{al}^{32}$ observed that individuals with WCH have higher levels of left ventricular mass index when compared to normotensives. This result corroborates with previous findings, which suggest that WCH subjects present an intermediate risk between normotensive and hypertension in children ${ }^{33}$ and adults ${ }^{34}$ for developing left ventricular hypertrophy ( $\mathrm{LVH})$. The prevalence of $\mathrm{LVH}$ found in individuals with $\mathrm{WCH}$ is $8 \%$, and it increases to $36 \%$ when associated with metabolic syndrome, ${ }^{35}$ contrasting with no case of LVH found in the control subjects for that analyses.

Hypertensive subjects also present a greater chance to develop renal damage. However, some studies have shown that children and elderly with WCH present no significant difference in albuminuria when compared to normotensives. ${ }^{36,37}$ Although few studies have explored this matter, these results may infer that patients with WCH have less renal involvement than individuals with established hypertension ${ }^{38}-$ though it can only be speculated.

\section{Masked hypertension}

$\mathrm{MH}$ is characterized as an inverse condition of $\mathrm{WCH}-$ adequate BP levels in the office $(<140 / 90 \mathrm{mmHg})$ but high levels outside the office by ABPM $(\geq 130 / 80 \mathrm{mmHg})$ or HBPM $(\geq 135 / 85 \mathrm{mmHg}) .{ }^{39}$ According to the ESH, this definition should be used only for those who do not treat hypertension. ${ }^{14}$

$\mathrm{MH}$ may be suspected in young individuals with normal $\mathrm{BP}$ in the office but who present with LVH, diabetes, and/or obesity, a family history of hypertension, many CVD factors, or even a high office BP at any moment. ${ }^{40}$ Currently, it is considered that the prevalence of $\mathrm{MH}$ varies between $15 \%$ and $30 \%{ }^{41}$ This phenomenon is strongly associated with the increased risk of atherosclerotic CVD in different populations ${ }^{41,42}$ and with an increased risk of morbidity and mortality for CVD. ${ }^{43-45}$

Most studies have compared $\mathrm{MH}$ with WCH because they were classified as "opposite" phenomena and, although both may present similar characteristics, it has been observed that $\mathrm{MH}$ is more related to TOD than $\mathrm{WCH}^{46}$

In relation to TOD, individuals with $\mathrm{MH}$ have thickening and lower complacency of the carotid artery in comparison with normotensive, despite no significant hemodynamic and BP differences when compared to hypertensive patients. ${ }^{47}$ It was also observed that individuals with untreated $\mathrm{MH}$ condition present a higher risk of left ventricular structural alterations compared to the normotensive counterparts. ${ }^{48}$

Hypertension presents harmful consequences for the patients, and interestingly, $\mathrm{MH}$ subjects are also accompanied by an increased risk of TOD ${ }^{11}$ followed by the subjects with $\mathrm{WCH}$. Additionally, $\mathrm{MH}$ and $\mathrm{WCH}$ conditions are independently associated with major $\mathrm{CV}$ events when compared to normotensives. $^{49}$

Taken together, the findings of most studies undoubtedly indicated that individuals with white coat syndrome have an increased TOD when compared with individuals with normal BP levels. It is suggested that the TOD development in subjects with white coat syndrome, primarily in $\mathrm{MH}$, could be close to the risk associated with hypertensive subjects (Figure 2).

\section{Diagnosis methods}

The clinical follow-up of patients with hypertension is extremely important for their prognostic. There are many methods for assessing BP. During a medical visit, office BP measurements should be performed by a physician or a trained health care professional according to the recommendations indicated by the current guidelines. ${ }^{10,14}$ The

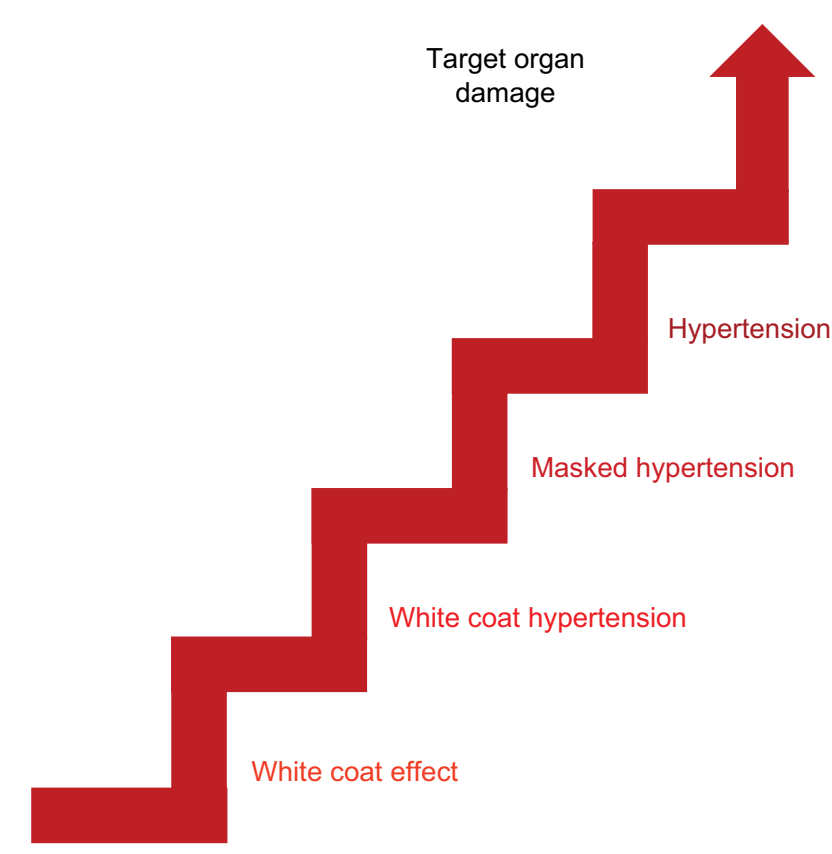

Normotension

Figure 2 Increase in TOD according to diagnosis of normotensive, white coat syndrome, and hypertension.

Note: TOD tends to increase among phenomena related to white coat syndrome, being more aggravating in hypertension.

Abbreviation: TOD, target organ damage. 
correct measurement is very important to properly diagnose hypertension or to modify the antihypertensive therapy. This procedure is common and essential in a hypertensive outpatient setting, either to diagnose or as a follow-up.

Questions raised in the SPRINT trial reinforce the importance of proper BP monitoring in and out of the office to avoid misdiagnosis. Currently, two well-accepted approaches are available to measure BP outside the office to detect the phenomena related to white coat syndrome: 1) HBPM and 2) ABPM. In HBPM method, the individuals can easily perform their BP measurement. It requires a prior training, usually given by the physician and using an appropriate validated device. This method presents some advantages because it is well accepted by the patients, besides presenting measurement accuracy and being cheaper than the ABPM. However, with this method, it is not possible to observe the pressure fluctuations during the patients' sleep period and also can present errors at the time of measurement due to the use of inaccurate devices and improper manipulation of the individual. ${ }^{50}$

ABPM is considered the best method to detect BP fluctuation. Recently, a large research conducted by Banegas ${ }^{45}$ concluded that ABPM is a better predictor of CV mortality as well as all-cause mortality than office-measured pressure. This oscillometric method is able to monitor the BP of patients for a period of 24 hours, providing more accurate BP measurements due to not only the mean BP obtained but also the diurnal and nocturnal variabilities. ${ }^{51}$ Moreover, ABPM does not depend on the patients' handling, provides more precise BP information on the individuals' routine, demonstrates nocturnal hypertension, evaluates the 24 hours efficacy of antihypertensive therapy, and as mentioned before, it is a strong predictor of $\mathrm{CV}$ morbidity and mortality compared with the office measurement. ${ }^{40}$ On the other hand, it presents some disadvantages such as reluctance of some patients to perform the examination due to the discomfort it causes and the possibility of inaccurate readings during the patients' activities that cause an imperfect reproducibility. ${ }^{40}$

Both HBPM and ABPM are indicated by the guidelines to identify cases of hypertension and white coat syndrome..$^{10,14}$ Due to the possibility of worsening $\mathrm{CV}$ prognosis and the development of TOD, individuals with $\mathrm{MH}, \mathrm{WCH}, \mathrm{WCE}$, or hypertension should be carefully pursued and diagnosed in order to favor appropriate therapeutic interventions.

\section{Conclusion}

Clinical trials reveal that we cannot underestimate the effects caused by the presence of "white coat" professionals, since they may be involved in increased CV risks and in the development of cardiac and vascular lesions. However, the methodological heterogeneity of the studies and errors related to the classification of these phenomena makes it difficult to prove the data available nowadays; therefore, more

Table I Associated features of normotension, white coat syndrome, and hypertension

\begin{tabular}{|c|c|c|c|c|c|c|}
\hline \multirow[t]{2}{*}{ Features } & \multirow[t]{2}{*}{ Normotension } & \multirow[t]{2}{*}{ White coat effect } & \multirow{2}{*}{$\begin{array}{l}\text { White coat } \\
\text { hypertension }\end{array}$} & \multirow[t]{2}{*}{ Masked hypertension } & \multicolumn{2}{|c|}{ Hypertension } \\
\hline & & & & & $\begin{array}{l}\text { Within } \\
\text { normal BP } \\
\text { limits }\end{array}$ & $\begin{array}{l}\text { Exceeding } \\
\text { normal BP } \\
\text { limits }\end{array}$ \\
\hline Office BP levels & $\leq 120 / 80 \mathrm{mmHg}^{16}$ & $\begin{array}{l}>20 / 10 \mathrm{mmHg} \text { when } \\
\text { compared to home } \\
\text { measurements }^{14}\end{array}$ & $\geq 140 / 90 \mathrm{mmHg}^{38}$ & $<140 / 90 \mathrm{mmHg}^{38}$ & $\begin{array}{l}<140 / 90 \\
\mathrm{mmHg}^{16}\end{array}$ & $\begin{array}{l}\geq 140 / 90 \\
m m H g^{15}\end{array}$ \\
\hline $\begin{array}{l}24 \text { hours ABPM } \\
\text { levels }\end{array}$ & $<130 / 80 \mathrm{mmHg}{ }^{16}$ & $<130 / 80 \mathrm{mmHg}{ }^{14}$ & $<130 / 80 \mathrm{mmHg}^{38}$ & $\geq 130 / 80 \mathrm{mmHg}^{38}$ & $\begin{array}{l}<130 / 80 \\
m m H g^{16}\end{array}$ & $\begin{array}{l}\geq 130 / 80 \\
\mathrm{mmHg}\end{array}$ \\
\hline HBPM levels & $<135 / 85 \mathrm{mmHg}^{16}$ & $\leq 135 / 85 \mathrm{mmHg}^{14}$ & $<135 / 85 \mathrm{mmHg}^{38}$ & $\geq 135 / 85 \mathrm{mmHg}^{38}$ & $\begin{array}{l}<135 / 85 \\
\mathrm{mmHg}^{16}\end{array}$ & $\begin{array}{l}\geq 135 / 85 \\
\mathrm{mmHg}^{15}\end{array}$ \\
\hline $\begin{array}{l}\text { Clinical } \\
\text { characteristics }\end{array}$ & - & $\begin{array}{l}\text { Higher heart rate } \\
\text { levels and BP non- } \\
\text { dipping condition }{ }^{17}\end{array}$ & $\begin{array}{l}\text { Higher in female sex, } \\
\text { obese, and it seems to } \\
\text { increase with respect } \\
\text { to age }\end{array}$ & $\begin{array}{l}\text { Increased risk of } \\
\text { atherosclerotic CVD, }{ }^{41} \\
\text { morbidity, and mortality } \\
\text { for CVD }\end{array}$ & \multicolumn{2}{|c|}{$\begin{array}{l}\text { Sustained elevated BP levels } \\
\text { are related to the development } \\
\text { of TOD and, consequently, } \\
\text { increased CV risk }\end{array}$} \\
\hline $\begin{array}{l}\text { Target organ } \\
\text { damage }\end{array}$ & - & $\begin{array}{l}\text { Low relationship with } \\
\text { TOD development; }{ }^{22} \\
\text { correlation with } \\
\text { arterial stiffness } \\
20,21\end{array}$ & $\begin{array}{l}\text { Correlation with } \\
\text { arterial stiffness }{ }^{28} \text { and } \\
\mathrm{LVH}^{34}\end{array}$ & $\begin{array}{l}\text { Presents a higher risk } \\
\text { of developing TOD } \\
\text { than other phenomena } \\
\text { but less risk than } \\
\text { hypertensive" }\end{array}$ & \multicolumn{2}{|c|}{$\begin{array}{l}\text { LVH, diastolic dysfunction, } \\
\text { carotid intima-media } \\
\text { thickening or plaque, renal } \\
\text { damage, and micro- as well as } \\
\text { macro-vascular alterations }\end{array}$} \\
\hline
\end{tabular}

Abbreviations: ABPM, ambulatory BP monitoring; BP, blood pressure; CV, cardiovascular risk; CVD, cardiovascular disease; HBPM, home BP monitoring; LVH, left ventricular hypertrophy; TOD, target organ damage. 
robust further studies should be carried out to evaluate such phenomena. Table 1 presents a summary of the associated characteristics of normotension, a phenomenon related to white coat syndrome and hypertension.

Finally, in the clinic, monitoring of hypertension and correct detection of WCH, WCE, and $\mathrm{MH}$, through methods such as ABPM and HBPM, are fundamental for therapeutic adequacy and consequent improvement of the prognosis of these individuals.

\section{Disclosure}

The authors report no conflicts of interest in this work.

\section{References}

1. Fryar CD, Ostchega Y, Hales CM, et al. Hypertension prevalence and control among adults: United States, 2015-2016. NCHS Data Brief. 2017;289:1-8.

2. Burt VL, Whelton P, Roccella EJ, et al. Prevalence of hypertension in the US adult population. Results from the Third National Health and Nutrition Examination Survey, 1988-1991. Hypertension. 1995;25(3):305-313.

3. Pickering TG, Gerin W, Schwartz AR. What is the white-coat effect and how should it be measured? Blood Press Monit. 2002;7(6):293-300.

4. Chobanian AV, Bakris GL, Black HR, et al; Joint National Committee on Prevention, Detection, Evaluation, and Treatment of High Blood Pressure. National Heart, Lung, and Blood Institute; National High Blood Pressure Education Program Coordinating Committee. Seventh report of the Joint National Committee on Prevention, Detection, Evaluation, and Treatment of High Blood Pressure. Hypertension. 2003;42(6):1206-1252.

5. Bloomfield, DA, Park, A. Decoding white coat hypertension. World $J$ Clin Cases. 2017;5(3):82-92.

6. Pickering, TG. Blood pressure measurement and detection of hypertension. Lancet. 1994;344(8914):31-35.

7. Mancia G, Bertinieri G, Grassi G, et al. Effects of blood-pressure measurement by the doctor on patient's blood pressure and heart rate. Lancet. 1983;2(8352):695-698.

8. Terracciano A, Scuteri A, Strait J, et al. Are personality traits associated with white-coat and masked hypertension? J Hypertens. 2014;32(10):1987-1992; discussion 1992.

9. Calhoun DA, Jones D, Textor S, et al. Resistant hypertension: diagnosis, evaluation, and treatment. A scientific statement from the American Heart Association Professional Education Committee of the Council for High Blood Pressure Research. Hypertension. 2008;51(6):1403-1419.

10. Whelton PK, Carey RM, Aronow WS, et al. 2017 ACC/AHA/AAPA/ ABC/ACPM/AGS/APhA/ASH/ASPC/NMA/PCNA Guideline for the Prevention, Detection, Evaluation, and Management of High Blood Pressure in Adults: A Report of the American College of Cardiology/ American Heart Association Task Force on Clinical Practice Guidelines. Hypertension. 2018;71(6):1269-1324.

11. Hänninen MR, Niiranen TJ, Puukka PJ, et al. Target organ damage and masked hypertension in the general population: the Finn-Home study. J Hypertens. 2013;31(6):1136-1143.

12. Palla M, Saber H, Konda S, Briasoulis A. Masked hypertension and cardiovascular outcomes: an updated systematic review and metaanalysis. Integr Blood Press Control. 2018;11:11-24.

13. Mancia G, Fagard R, Narkiewicz K, et al; Task Force Members. 2013 ESH/ESC Guidelines for the management of arterial hypertension: the Task Force for the management of arterial hypertension of the European Society of Hypertension (ESH) and of the European Society of Cardiology (ESC). J Hypertens. 2013;31(7):1281-1357.
14. Williams B, Mancia G, Spiering W, et al; Authors/Task Force Members. 2018 ESC/ESH Guidelines for the management of arterial hypertension: The Task Force for the management of arterial hypertension of the European Society of Cardiology (ESC) and the European Society of Hypertension (ESH). 2018; 36(10):1953-2041.

15. Wright JT Jr, Whelton PK, Reboussin DM. A randomized trial of intensive versus standard blood-pressure control. $N$ Engl $J$ Med. 2016;374(23):2294.

16. Celis H, Fagard RH. White-coat hypertension: a clinical review. Eur $J$ Intern Med. 2004;15(6):348-357.

17. Malachias MVB, Gomes MAM, Nobre F, et al. 7th Brazilian Guideline of Arterial Hypertension: Chapter 2 - Diagnosis and Classification. Arq Bras Cardiol. 2016;107(3 Suppl 3):7-13. English, Portuguese.

18. Bochud M, Bovet P, Vollenweider P, et al. Association between whitecoat effect and blunted dipping of nocturnal blood pressure. Am J Hypertens. 2009;22(10):1054-1061.

19. Cuspidi C, Meani S, Salerno M, et al. Cardiovascular target organ damage in essential hypertensives with or without reproducible nocturnal fall in blood pressure. J Hypertens. 2004;22(2):273-280.

20. Modolo R, Ruggeri Barbaro N, de Faria AP, et al. The white-coat effect is an independent predictor of myocardial ischemia in resistant hypertension. Blood Press. 2014;23(5):276-280.

21. de Simone G, Schillaci G, Chinali M, et al. Estimate of white-coat effect and arterial stiffness. J Hypertens. 2007;25(4):827-831.

22. Fujita H, Matsuoka S, Awazu M. White-Coat and Reverse WhiteCoat Effects Correlate with 24-h Pulse Pressure and Systolic Blood Pressure Variability in Children and Young Adults. Pediatr Cardiol. 2016;37(2):345-352.

23. Kristensen KS, Høegholm A, Bang LE, et al. No impact of blood pressure variability on microalbuminuria and left ventricular geometry: analysis of daytime variation, diurnal variation and 'white coat' effect. Blood Press Monit. 2001;6(3):125-131.

24. Figueiredo VN, Martins LC, Boer-Martins L, et al. The white coat effect is not associated with additional increase of target organ damage in true resistant hypertension. Med Clin (Barc), 2013;140(1):1-5.

25. Cuspidi C, Sala C, Grassi G, Mancia G. White coat hypertension: to treat or not to treat? Curr Hypertens Rep. 2016;18(11):80.

26. Mancia G, Bombelli M, Facchetti R, et al. Long-term risk of sustained hypertension in white-coat or masked hypertension. Hypertension. 2009;54(2):226-232.

27. Barochiner J, Aparicio LS, Alfie J, et al. Arterial Stiffness in Treated Hypertensive Patients With White-Coat Hypertension. J Clin Hypertens (Greenwich). 2017;19(1):6-10.

28. Sung SH, Cheng HM, Wang KL, et al. White coat hypertension is more risky than prehypertension: important role of arterial wave reflections. Hypertension. 2013;61(6):1346-1353.

29. Andrikou I, Tsioufis C, Dimitriadis K, et al. Similar levels of low-grade inflammation and arterial stiffness in masked and white-coat hypertension: comparisons with sustained hypertension and normotension. Blood Press Monit. 2011;16(5):218-223.

30. Erdogan D, Caliskan M, Gullu H, et al. Aortic elastic properties and left ventricular diastolic function in white-coat hypertensive individuals. Blood Press Monit. 2006;11(4):191-198.

31. Longo D, Zaetta V, Perkovic D, et al. Impaired arterial elasticity in young patients with white-coat hypertension. Blood Press Monit. 2006;11(5):243-24.

32. Androulakis E, Papageorgiou N, Lioudaki E, et al. Subclinical Organ Damage in White-Coat Hypertension: The Possible Role of Cystatin C. J Clin Hypertens (Greenwich). 2017;19(2):190-197.

33. Lande MB, Meagher CC, Fisher SG, et al. Left ventricular mass index in children with white coat hypertension. J Pediatr. 2008;153(1):50-54.

34. Ihm SH, Youn HJ, Park CS, et al. Target organ status in white-coat hypertensives: usefulness of serum procollagen type I propeptide in the respect of left ventricular diastolic dysfunction. Circ J. 2009;73(1):100-105.

35. Mulè G, Nardi E, Cottone $S$, et al. Metabolic syndrome in subjects with white-coat hypertension: impact on left ventricular structure and function. J Hum Hypertens. 2007;21(11):854-860. 
36. Seeman T, Pohl M, Palyzova D, John U. Microalbuminuria in children with primary and white-coat hypertension. Pediatr Nephrol. 2012;27(3):461-467.

37. Di Mauro S, Spallina G, Scalia G, et al. Urinary albumin excretion in elderly patients with white coat hypertension. Arch Gerontol Geriatr. 1999;28(1):23-29.

38. Høegholm A, Bang LE, Kristensen KS, Nielsen JW, Holm J. Microalbuminuria in 411 untreated individuals with established hypertension, white coat hypertension, and normotension. Hypertension. 1994;24(1): $101-105$.

39. Kang YY, Li Y, Huang QF, et al. Accuracy of home versus ambulatory blood pressure monitoring in the diagnosis of white-coat and masked hypertension. J Hypertens. 2015;33(8):1580-1587.

40. O'Brien E, Parati G, Stergiou G, et al; European Society of Hypertension Working Group on Blood Pressure Monitoring. European Society of Hypertension position paper on ambulatory blood pressure monitoring. J Hypertens. 2013;31(9):1731-1768.

41. Peacock J, Diaz KM, Viera AJ, Schwartz JE, Shimbo D. Unmasking masked hypertension: prevalence, clinical implications, diagnosis, correlates and future directions. J Hum Hypertens. 2014;28(9):521-528.

42. Anstey DE, Booth JN 3rd, Abdalla M, et al. Predicted Atherosclerotic Cardiovascular Disease Risk and Masked Hypertension Among Blacks in the Jackson Heart Study. Circ Cardiovasc Qual Outcomes, 2017;10(7):e003421.

43. Asayama K, Thijs L, Li Y, et al; International Database on Ambulatory Blood Pressure in Relation to Cardiovascular Outcomes (IDACO) Investigators.. Setting thresholds to varying blood pressure monitoring intervals differentially affects risk estimates associated with whitecoat and masked hypertension in the population. Hypertension. 2014;64(5):935-942.
44. Fagard RH, Cornelissen A. Incidence of cardiovascular events in whitecoat, masked and sustained hypertension versus true normotension: a meta-analysis. J Hypertens. 2007;25(11):2193-2198.

45. Banegas JR, Ruilope LM, de la Sierra A, et al. Relationship between Clinic and Ambulatory Blood-Pressure Measurements and Mortality. N Engl J Med. 2018;378(16):1509-1520.

46. Yoon HJ, Ahn Y, Park JB, et al. Are metabolic risk factors and target organ damage more frequent in masked hypertension than in white coat hypertension? Clin Exp Hypertens. 2010;32(7):480-485.

47. Scuteri A, Morrell CH, Orru' M, et al. Gender specific profiles of white coat and masked hypertension impacts on arterial structure and function in the SardiNIA study. Int J Cardiol. 2016;217:92-98.

48. Cuspidi C, Sala C, Tadic M, et al. Untreated masked hypertension and subclinical cardiac damage: a systematic review and meta-analysis. $\mathrm{Am}$ J Hypertens. 2015;28(6):806-813.

49. Tientcheu D, Ayers C, Das SR, etal. Target Organ Complications and Cardiovascular Events Associated With Masked Hypertension and White-Coat Hypertension: Analysis From the Dallas Heart Study. $J$ Am Coll Cardiol. 66(20):2159-2169.

50. Parati G, Stergiou GS, Asmar R, et al; ESH Working Group on Blood Pressure Monitoring. European Society of Hypertension practice guidelines for home blood pressure monitoring. J Hum Hypertens. 2010;24(12):779-785.

51. Sociedade Brasileira de Cardiologia (SBC); Sociedade Brasileira de Hipertensão (SBH); Sociedade Brasileira de Nefrologia (SBN). V Diretrizes Brasileiras de Monitoração Ambulatorial Da Pressão Arterial (MAPA V) e III Diretrizes de Monitoração Residencial da Pressão Arterial (MRPA III) [V Guidelines for ambulatory blood pressure monitoring (ABPM) and III Guidelines for home blood pressure monitoring (HBPM)]. Arq Bras Cardiol. 2011;97(3 Suppl 3):1-24. Portuguese.
Integrated Blood Pressure Control

\section{Publish your work in this journal}

Integrated Blood Pressure Control is an international, peer-reviewed open-access journal focusing on the integrated approach to managing hypertension and risk reduction. Treating the patient and comorbidities together with diet and lifestyle modification and optimizing healthcare resources through a multidisciplinary team approach constitute key

\section{Dovepress}

features of the journal. This journal is indexed on American Chemical Society's Chemical Abstracts Service (CAS). The manuscript management system is completely online and includes a very quick and fair peerreview system, which is all easy to use. Visit http://www.dovepress.com/ testimonials.php to read real quotes from published authors. 